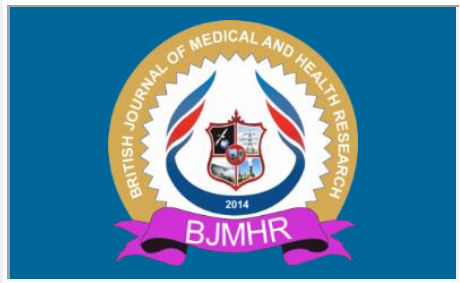

\title{
BJMHR
}

British Journal of Medical and Health Research

Journal home page: www.bjmhr.com

\section{Evaluation of Result of Anterior Cervical Discectomy and Fusion by Standalone PEEK cage in cervical Spondylotic Myeloradiculopathy.}

\section{Md. Anowarul Islam ${ }^{*}$, Md. Shohidullah', Wayez Mahbub ${ }^{1}$, Abu Zaffar Chowdhury ${ }^{1}$ 1.Spine surgery, Dept. of Orthopaedics, Bangabandhu Sheikh Mujib Medical University, Dhaka, Bangladesh.}

\section{ABSTRACT}

Cervical spondylotic myeloradiculopathy is a common cause of neck pain and radiating arm pain which develops when one or more of the intevertebral discs in the cervical spine start to degenerate. Multiple techniques and modalities of fixation are used in Anterior Cervical Discectomy and interbody Fusion (ACDF), among them use of standalone PEEK cage is standard one. To evaluate the result of ACDF by standalone PEEK cage for degenerative cervical disc disease. This prospective study was conducted in the Department of Orthopaedics, BSMMU, Dhaka from July 2015 to June 2020. A total number of 64 (40 male and 24 female) patients with cervical spondylotic myeloradiculopathy with single or two level involvement confirmed by MRI were selected for the study who were failed to improve after conservative treatment. Modified Odom's criteria, visual analogue scale(VAS), Nurick Grading and bridwell criteria for cervical spondylotic myelopathy was used for evaluation of the results. Mean age of the patients was $51.6 \pm 7.42$ years. Most of the patients were farmers 24 (37.5\%). Single level involvement was in 38(59.4\%) cases and two level involvement were in 26(40.6\%) cases. Most commonly involved level was $\mathrm{C}_{5 / 6}(35$ cases, 55\%). Preoperative VAS score was $7.66 \pm$ 0.53 which significantly reduced to $1.22 \pm 0.31$ after 12 months of operation. Grade I fusion was observed in 53(82.8\%) patients in 12 months by Bridwell grade of fusion. Acording to modified Odom's criteria, postoperative outcome at 12 months of follow up, 51(79.7\%) patients showed excellent, 11(17.2\%) patients showed good outcome and 2(3.1\%) showed fair outcome. No poor outcome was found. P value was 0.003. ACDF is the best technique for the treatment of cervical disc disease with excellent functional outcome which is achieved by using standalone PEEK cage. This can be used with minimum risk as well excellent fusion rate.

Keywords: Cervical spondylotic myeloradiculopathy, ACDF, standalone PEEK cage.

*Corresponding Author Email: maislam.spine@gmail.com

Received 29 October 2020, Accepted 16 December 020

Please cite this article as: Islam MD et al., Evaluation of Result of Anterior Cervical Discectomy and Fusion by Standalone PEEK cage in cervical Spondylotic Myeloradiculopathy.. British Journal of Medical and Health Research 2020. 


\section{INTRODUCTION}

Cervical spondylotic myeloradiculopathy is a disorder of spinal cord accompanying typical age related degeneration of the cervical vertebrae and intervertebral disc ${ }^{1}$. Myelopathic or upper motor neuron lesion findings (e.g. hyper reflexia and gait disturbance) are the typical manifestations and the most common cause of disorder of spinal cord in aged patients ${ }^{2}$. Other manifestation is radiculopathy due to degenerative process includes bulging of annulus and tear, herniation of disc material into the canal to produce pressure effect over the spinal cord and nerve roots ${ }^{3}$.

Myelopathic hand sign, Grip release sign, Hoffman's sign, Romberg test along with gait disturbances (broad based and hesitant) are common in advanced conditions. Changes in the pattern of bladder and bowel dysfunction are also found in about $20 \%-50 \%$ of the patients ${ }^{4}$ Interbody fusion provides limitation of abnormal painful motion in the spine. Recent treatment modality concluded that interbody fusion is the best treatment option in cervical prolapsed intervertebral disc. Interbody fusion rate is about $92 \%$ by anterior cervical discectomy and fusion (ACDF) ${ }^{5}$. A lot of techniques for performing ACDF depending on surgeon preference are available. Cervical cages of different materials have been used as titanium, PEEK cage and carbon fiber ${ }^{8}$. ACDF with PEEK cage provide good functional outcome and fusion rate after surgery ${ }^{9}$.

\section{MATERIALS AND METHOD}

This prospective study was carried out at the Department of Orthopaedic Surgery, BSMMU, Shahbag, Dhaka from July 2015 to June 2020. A total number of 64 patients with cervical spondylotic myeloradiculopathy with single or two level involvement confirmed by MRI were selected for the study who were failed to improve after conservative treatment. Patients having involvement of more than two level, tandem stenosis, infection, tumor or fracture of vertebra were excluded from the study. Patients were followed up at 3 months, 6 months, 12 months and finally at 24 months. The pain category was scored using a VAS ${ }^{10}$, Nurick scale was used for myelopathy ${ }^{11}$, pre-operative and post-operative Odom's criteria for functional outcome ${ }^{12}$ and Bridwell criteria for Fusion ${ }^{13}$.

\section{Surgical procedure}

Patient was in supine positioned. The Gardener-wells tong traction was applied. A sandbag was placed in the inter scapular area to keep the neck in slight extension. Transverse skin incisions over the targeted vertebral level was performed. The platysma was identified and incised. The esophagus was identified and retracted medially, while the sternocleidomastoid and underlying carotid sheath was retracted laterally. The prevertebral fascia was divided, and the longus colli was further retracted. Intraoperative radiographs was obtained to confirm the appropriate 
cervical level. The offending disc was removed with rongeur. As the posterior aspect of the vertebral body was reached, osteophytes was removed. The entire disc, vertebral body endplates was decorticated. Standalone PEEK cage inserted and fixed with screw after measuring with template. Position was checked by fluoroscope. Then after proper haemostasis, longus colli muscle along with cut edge of anterior longitudinal ligament were approximated, omohyoid muscle was repaired, platysmal layer, subcutaneous layer and skin were closed in layer. Sterile dressing was given and cervical orthosis was applied before extubation.

\section{Statistical analysis}

All the data were compiled and sorted properly and the quantitative data was analyzed statistically by using Statistical Package for Social Science (SPSS-22). The results were expressed as percentage and mean $\pm \mathrm{SD}$ and $\mathrm{p}<0.05$ was considered as the level of significance. Comparison of continuous variables was made with Student's t-tests. Comparison of categorical data was made with Chi-Square tests.

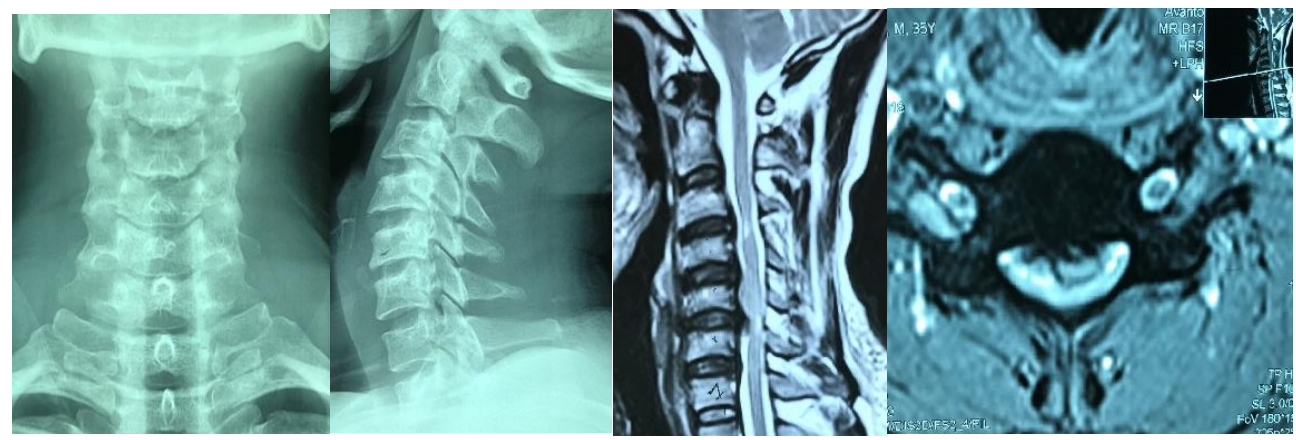

Figure 1: Preoperative $x$-ray and MRI of cervical spine showing disc space reduction in C5/6 space and prolapse of $\mathrm{C5/6}$ disc causing compression to the spinal cord with myelomalacic change.

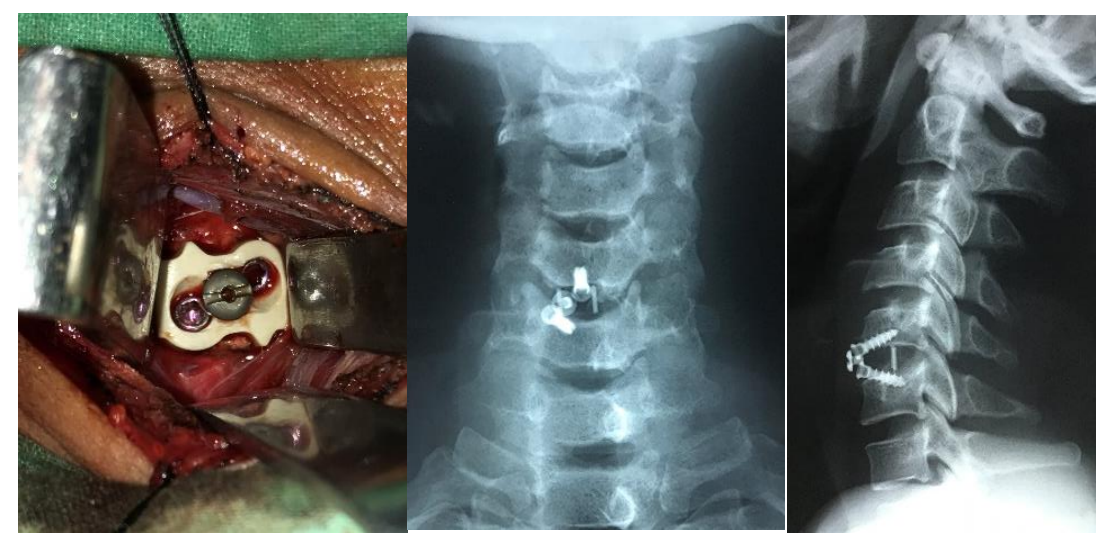

Figure 2: Peroperative image and postoperative $x$-ray showing placement of standalone PEEK cage with screw.

\section{RESULTS AND DISCUSSION}

Mean age of the patients was $51.6 \pm 7.42$ years, Highest and lowest age were 67 and 44 years. Most of the patients were found in the age of $51-60$ years. 40 patients $(62.5 \%)$ were male and 
24 patients (37.5\%) were female. Most of the patients were farmers $24(37.5 \%)$. Others include housewife 17 (26.6\%), business 12 (18.75\%), day labour 7 (10.9\%) and service man 4 (6.25\%). Single level involvement was in 38(59.4\%) cases and two level involvement were in $26(40.6 \%)$ cases. Most commonly involved level was $\mathrm{C}_{5 / 6}(35$ cases, $55 \%)$, then $\mathrm{C}_{6 / 7}, \mathrm{C}_{4 / 5}$ and $\mathrm{C}_{3 / 4}$ disc level respectively. Transient dysphagia was seen $2(3.1 \%)$ patients and transient paraparesis was developed in 1 (1.67\%) patient. Postoperative paresthesia developed in 2 patients $(3.1 \%)$ in 1 month who were recovered within 3 months. Average operating time was 2.1 hours and average postoperative hospital stay was 5.3 days

According to Nurick grading, out of 64 patients, 49(76.6\%) patients found in grade 3 and $15(23.4 \%)$ patients in grade 4. Preoperative VAS score was $7.66 \pm 0.53$ which significantly reduced to $1.22 \pm 0.31$ after 12 months of operation. Grade I fusion was observed in 53(82.8\%) patients in 12 months by Bridwell grade of fusion (Table I). According to modified Odom's criteria (Table II), postoperative outcome at 12 month of follow up, 51(79.7\%) patients showed excellent, 11(17.2\%) patients showed good outcome and 2(3.1\%) showed fair outcome. No poor outcome was found. $\mathrm{P}$ value was 0.003 .

Table I: Distribution of study subjects according to Bridwell grading system

\begin{tabular}{lllll}
\hline Bridwell Grade & 3 months & 6 months & 12 months & P value \\
\hline I & $29(45.3 \%)$ & $42(65.6 \%)$ & $53(82.8 \%)$ & 0.007 \\
II & $25(39.1 \%)$ & $18(28.1 \%)$ & $12(18.75 \%)$ & \\
III & $10(15.6 \%)$ & $4(6.25 \%)$ & $1(1.7 \%)$ & \\
IV & 0 & 0 & 0 & \\
\hline
\end{tabular}

Table II: Distribution of study subjects according to modified Odom's criteria

\begin{tabular}{lllll}
\hline Modified Odom's criteria & 3 months & 6 months & 12 months & P value \\
\hline Excellent & $32(50.0 \%)$ & $44(68.7 \%)$ & $51(79.7 \%)$ & 0.003 \\
Good & $21(32.8 \%)$ & $16(25.0 \%)$ & $11(17.2 \%)$ & \\
Fair & $11(17.2 \%)$ & $4(6.25 \%)$ & $2(3.1 \%)$ & \\
Poor & 0 & 0 & 0 & \\
\hline
\end{tabular}

Mean age of the patients was $51.6 \pm 7.42$ years, Highest and lowest age were 67 and 44 years. Most of the patients were found in the age of $51-60$ years. Spallone A et al. 2014 found mean age of their study subjects was $49.1 \pm 12.1$ years ${ }^{14}$.

40 patients $(62.5 \%)$ were male and 24 patients $(37.5 \%)$ were female. Most of the patients were farmers 24 (37.5\%). Others include housewife 17 (26.6\%), business 12 (18.75\%), day labour $7(10.9 \%)$ and service man $4(6.25 \%)$. Islam MA et al, 2012 showed sedentary workers $(43.75 \%)$, heavy worker $(18.75 \%)$ and housewife $(37.5 \%){ }^{15}$.

Single level involvement was in 38(59.4\%) cases and two level involvement were in 26(40.6\%) cases. Most commonly involved level was $\mathrm{C}_{5 / 6}\left(35\right.$ cases, $55 \%$ ), then $\mathrm{C}_{6 / 7}, \mathrm{C}_{4 / 5}$ and $\mathrm{C}_{3 / 4}$ disc level respectively. Abdullah et al. 2016 showed in their study highest number of patients in the level of $\mathrm{C}_{5 / 6}$ and among them 1 patient (8.3\%) in cage group and 4 patients (33.3\%) in plate 
group ${ }^{17}$. Ayman et al. 2013 showed that regarding the levels operated; there were 14 patients in $\mathrm{C}_{3 / 4}$ level, 18 patients in $\mathrm{C}_{4 / 5}$ level, 26 patients in $\mathrm{C}_{5 / 6}$ level and 4 patients in $\mathrm{C}_{6 / 7}$ level ${ }^{16}$. Transient dysphagia was seen $2(3.1 \%)$ patients and transient paraparesis was developed in 1 $(1.67 \%)$ patient. Postoperative paresthesia developed in 2 patients (3.1\%) in 1 month who were recovered within 3 months. Ayman et al. 2013 stated that there were some transient complications; dysphagia was reported in 5 patients $(12.5 \%)$ which was improved within the first 2 weeks ${ }^{16}$.

Preoperative VAS score was $7.66 \pm 0.53$ which significantly reduced to $1.22 \pm 0.31$ after 12 months of operation. Similar result found by Spallone et al. ${ }^{14}$. According to Nurick grading, out of 64 patients, 49(76.6\%) patients found in grade 3 and 15(23.4\%) patients in grade 4 preoperatively. Post operatively at 12 month, 58 patients (90.6\%) in grade 0 level (excellent) and 6 patients (9.4\%) in grade 1 level (Good). Smith and Robinson, 1958 outcome obtained as excellent in $64.2 \%$, good in $14.2 \%$, fair in $14.2 \%$ and poor in $7.1 \%$. As a whole satisfactory outcome was $78.4 \%{ }^{18}$. According to modified Odom's criteria (Table II), postoperative outcome at 12 month of follow up, 51(79.7\%) patients showed excellent, 11(17.2\%) patients showed good outcome and 2(3.1\%) showed fair outcome. No poor outcome was found. P value was 0.003 . Similar result found by Chou YC et al. and Spallone et al ${ }^{8,14}$

\section{CONCLUSION}

After analyzing the result, it can be concluded that ACDF with standalone PEEK cage can be an ideal technique for treatment of patients with cervical spondylotic myeloradiculopathy with excellent postoperative outcome and good fusion rate.

\section{ETHICAL ISSUE}

Informed written was taken from the patients. Confidentiality, privacy of the patients ensured with respect and responsibility.

\section{REFERENCES}

1. Bohlman HH, and Emery SE. The pathophysiology of cervical spondylosis and myelopathy. Spine 1988, 13: 843-6.

2. Dillin WH. Clinical syndromes in cervical myelopathy. In: The Spine. 5th ed. Philadelphia: W.B. Saunders; 2006: 775-88.

3. Baron EM, Young WF. Cervical spondylotic myelopathy: a brief review of its pathophysiology, clinical course and diagnosis. Neurosurgery. 2007; 60(1 Suppl 1): S35-S41.

4. Abbed KM, Coumans JV. Cervical radiculopathy: pathophysiology, presentation and clinical evaluation. Neurosurgery. 2007; 60(Suppl 1): S28-S34 
5. Yang JJ, Yu CH, Chang BS, Yeom JS, Lee JH, Lee CK. Subsidence and nonunion after anterior cervical interbody fusion using a stand-alone polyetheretherketone (PEEK) cage. Clin Orthop Surg. 2011; 3: 16-23.

6. Cloward R.B.: The anterior approach for removal of ruptured cervical disc. J. Neurosurg., 15: 602-617, 1956. J Dhaka Med Coll. Vol. 25, No. 2. October, 2016113

7. Aronson NI. The management of soft cervical disc protrusions using the SmithRobinson approach. Clin. Neurosurg., 20: 253-258, 1973.

8. Chou Y.C., Chen D.C., Hsieh W.A., Chen W.F., Yen P.S., Harnod T., Chiou T.L., Chang Y.L., Su C.F., Lin S.Z. And Chen S.Y.: Efficacy of anterior cervical fusion: Comparison of titanium cages, polyethere-therketone (PEEK) cages and autogenous bone grafts. J. Clin. Neurosci., 15: 1240-1245, 2008.

9. Islam MA, Hossain MA, Iqbal AA, Parvez MQ, Ahsanuzzaman M and Ahammed S. Anterior cervical discectomy and fusion with polyetherether ketone cages in the management of single and double level cervical spondylotic myelopathy-our experiences of 80 cases. KYAMC Journal. 2018; 9(1):32-34

10. Huskisson EC: Measurement of pain. J. Rheumatol.1982; 9:768-769. 11.

11. Nurick: The pathogenesis of the spinal cord disorder associated with cervical spondylosis. Brain.1972; 95:87- 100. 12.

12. Odom GL, Finney W, Woodhall B: Cervical disc lesions. JAMA.1958; 166:23-28.

13. Kim SY, Park KS, Jung KS, Chung SY, Kim SM, Park MS and Kim HK. An Early Comparative Analysis of the Use of Autograft versus Allograft in Anterior Cervical Discectomy and Fusion. Korean J Spine 9(3):142-146, 2012

14. Spallone A and Marchione P. Anterior cervical discectomy and fusion with "miniinvasive" harvesting of iliac crest graft versus polyetheretherketone (PEEK) cages: A retrospective outcome analysis. ELSEVIER International Journal of Surgery, 2014; 12: $1328-1332$.

15. Islam MA, Habib MA, Sakeb N. Anterior Cervical Discectomy, Fusion and stabilization Bangladesh Medical Research Council Bulletin, 2012; 38: 62-66.

16. Ayman EA, Galhom MD. Comparison between polyetheretherketone (PEEK) cages versus an iliac crest autograft used in treatment of single or double level anterior cervical discectomy. Med J Cairo Univ, , 2013; 81(2): 9 - 17.

17. Abdallah A, Taha AM. Cages or plates for anterior interbody fusion for cervical radiculopathy: single and double levels. The Egyptian Orthopaedic Journal, 2016; 51: $65-70$. 
18. Smith GW and Robinson RA. The treatment of certain cervical-spine disorders by anterior removal of the intervertebral disc and interbody fusion. JBJS, 1958; 40(3): 607-624.

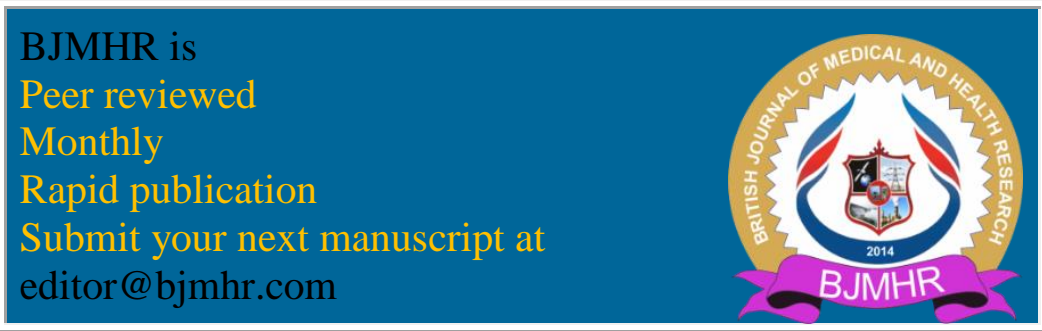

